\title{
Improving Losses Distribution Approach for operational risk using fuzzy numbers
}

\author{
Assem Tharwat ${ }^{1}$, Ramadan A. ZeinEldim² ${ }^{2}$ Hamiden A. Wahed Khallifa ${ }^{3}$, Ahmed M. Saleim ${ }^{4}$ \\ ${ }^{1}$ College of Business Administration, American University of the Emirates, Dubai, United Arab \\ Emirates, assem.tharwat@aue.ae \\ ${ }^{2}$ Deanship of Scientific Research, King Abdul Aziz University, Kingdom of Saudi Arabia, \\ rzainaldeen@kau.edu.sa \\ ${ }^{3}$ Institute of Statistical Studies \& Research, Cairo University, Egypt, Hamiden_2008@yahoo.com \\ ${ }^{4} \mathrm{PhD}$ Researcher, Institute of Statistical Studies \& Research, Cairo University, Egypt, \\ aalywa@banquemisr.com
}

\section{Abstract}

Estimating the required capital to meet operational risk is very important to banking especially with increasing unexpected events (internal or external), which may cause the collapse of the banks. Banks can use Basic Indicator Approach (BIA), Standardized Approach (SA) or Advanced Measurement Approach (AMA) to quantify operational risk and estimate the required capital to meet it. Under AMA, Loss Distribution Approach (LDA) consider the most theoretical and common technique. LDA suffer from some obstacles that may affect in its accuracy. Fuzzy will be used to improve LDA. The application of the proposed method shown that, the obtained results are more reliable.

Keywords: operational risk, loss distribution approach, risk measure, fuzzy number, value at risk, $\alpha$ cut.

\section{Introduction}

Operational risk incorporates many types of risk. Risk events in operational risk characterized by low frequency/high impact and high frequency/low impact. During measure operational risk, banks must study the effect both types of events. According to Basel committee, the operational risk can be measured using three methods. Basic Indictor Approach (BIA), Standardized Approach (SA) and Advanced Measurement Approach (AMA). BIA and SA realize that the size of bank activities reflect the size of the risk, which may the bank faced so both approaches use gross income to measure the operational risk. The third approach uses the actual loss to measure operational risk.

To find the capital to meet operational risk, under Advanced Measurement Approach, we need to do two steps. The first one is to estimate the expected operational loss. The most common and theoretical method to achieve these step is Loss Distribution Approach (LDA). The second step, after find expected losses we need to maps these losses to single number that represent the required capital to meet future loss. These done by using what is called risk measure. The supreme common risk measure is Value at Risk and Expected Shortfall. To estimate the required capital accurately, the expected losses in the first step must be estimated accurately. In this paper, fuzzy will be used to improve LDA in order to estimate required capital to meet operational risk reflect both types of event in operational risk (low frequency/high impact and high frequency/low impact).

The paper organized as follows. Section 2 gives theoretical background about operational risk. Section 3 is assigned to the literature review. Section 4 reviews the loss distribution approach and present the motivation to improve it. Section 5 presents preliminaries to fuzzy mathematics which will use in further sections. The proposed method and the application are presented in section 6 . Conclusions are given in section 7 . 
DOI: https://dx.doi.org/10.26808/rs.ca.i8v3.03 International Journal of Computer Application (2250-1797)

Issue 8 Volume 3, May-June 2018

2. Theoretical background

\subsection{Operational risk}

Based on Basel Committee on Banking Supervision (BCBS) risk categorized into three main groups credit risk, market risk, and operational risk, [25]. Operational Risk (OR) is approximately newly defined branch of risk. Operational risk includes many different types of risk not included in market risk or credit risk. There are many different definitions to operational risk; the accepted definition for operational risk given by Basel II. According to Basel II operational risk defines as "the risk of loss resulting from failed or inadequate internal processes, systems and people or from external events. In credit and market risk there are an acceptable models to measure risk, in contrast it is difficult to build a model in operational risk and get the acceptance such as credit and market risk models. Many authors ascribe these to the complexity of operational risk origin and lack of historical data, $[19,15,16]$.

\subsection{Measurement operational risk methods}

According to, the Basel II framework, there are three methods can be used to quantify the operational risk, Basic Indictor Approach (BIA), Standardized Approach (SA) and Advanced Measurement Approach (AMA) [1, 4, 15, 16, 19, 28].

Basic Indictor Approach (BIA) based on annual revenue of the bank. In BIA the required capital is determined according to a fixed proportion (set by the Basel Committee) of gross income so it's considered as top-down approaches. Standardized Approach (SA) based on annual income of each of the broad business lines of the bank. In SA the required capital is determined according to a fixed proportion (set by the Basel Committee) of gross income in each business line so its consider a top-down approaches.

According to the Advanced Measurement Approach (AMA), banks use internal operational risk measurement techniques to determine the required capital to meet operational losses. There are different techniques can be used under the AMA and there is no standard technique imposed by Basel. Thus, the banks can develop their own models, the bank must ensure that its measurement technique are reliable and accurate but using the estimated capital for regulatory purpose depending on supervisory approval, [4, 15]. Under the AMA, Basel proposes eight business lines and seven event type classes to collect the operational risk data. Therefore, the AMA technique used by a bank will use operational loss data saved in a matrix of eight business lines and seven event types. The banks can build risk cell according to its activities but must be able to transfer these cells to the Basel risk cells, $[19,15]$.

There are a many techniques present as Advanced Measurement Approach (AMA) for operational risk but there is a debate about the list of techniques belonging to the AMA. The techniques which classified as advanced measurement approach includes Scenario Analysis, Key Risk Indicators, Risk Control Self-Assessment, Loss Distribution Approach, Extreme Value Theory (EVT), Bayesian inference, Dynamic Bayesian networks, Expectation Maximization algorithms, Internal Measurement Approach (IMA), and Scorecard Approach (SCA), [15, 4, 7].

\section{Literature review}

Pavel V., et al [20], uses Bayesian inference to combine expert opinions and historical data to quantify operational risk. Dominik D., et al. [3] suggested a new method to quantify required capital for operational risk based on Bayesian inference method. Pavel V., et al use Bayesian inference to combine different source of data, expert opinion, internal data, and external data to quantification of the frequency and severity distributions. Kashfia N., et al. [11], uses Bayesian inference method to calculate the total capital for a bank to cover the operational risk.

Marcelo C., et al. [12] apply extreme value theory, which applied to market and credit risk management problems, to study the behavior of the tail of the distribution of operational loss and find the economic capital to cover operational risk. Hylmun Izhar [6] proposed a model to measure operational risk based on Delta-Gamma Sensitivity Analysis and Extreme Value Theory and called the model DGSA-EVT. Ognjen V. [17] develops and implements a model that can mimic 
DOI: https://dx.doi.org/10.26808/rs.ca.i8v3.03 International Journal of Computer Application (2250-1797)

Issue 8 Volume 3, May-June 2018

operational risk in insurance. The author analysis severity at two levels the tail and the body. The body can be modeled by using a parametric distribution and analyses the tail by applying extreme value theory. Then, the convolution method can be used to combine the tail and the body of the distribution.

Milan R. and Petr T. [14] attempt to determine which statistical method is better to model the operational loss and estimate the required capital. They suggested that the most suitable one for modeling operational risk is g\&h distribution. Ariane C., et al [2] introduces a comprehensive Loss Distribution Approach framework for measurement operational risk. In addition, they propose a method to integrate external data in the framework. Valérie C., et al. [26] develops a methodology to model loss data depending on covariates. They model the frequency of operational loss using a non-homogeneous Poisson process with rate function and model the severity using a non-stationary generalized Pareto distribution.

Kabir K. and David F. [10] proposed a method to measure operational risk using scenario analysis and internal operational loss data. They evaluate the impact of each scenario on the estimated required capital using the Change of Measure approach (COM) which used in market risk.

Antonina D. and Alexey T. [1] use fuzzy number to evaluate operational risk levels for the scenarios obtained from experts and estimate operational risk capital. Shuxia Liu and Haijie Mi [23], introduce a new method to measure operational risk they use fuzzy point inference to quantify the parameter of the frequency and severity distribution.

E. Karam and F. Planchet [4], present different theories and approaches to model the operational risk. They concluded that, although the standardized approach is commonly applied by banks, applying more advanced techniques, such as the Extreme Value Theory, Loss Distribution Approach, or Bayesian techniques might offer framework to model operational risk, and the determined capital will be more robust.

Generally, there is several alternatives techniques use the historical operational loss (within the AMA) to quantify operational risk in order to estimate the required capital. The most common and more sophisticated technically is the Loss Distribution Approach (LDA), so many banks agree to use this approach to estimate operational risk and quantify the required capital, [5, 27, 2, 3].

\section{Losses Distribution Approach (LDA)}

\subsection{Introduction to Losses Distribution Approach (LDA)}

According to the Advanced Measurement Approach (AMA), the Loss Distribution Approach (LDA) is the most common method used to measure operational risk. LDA is a frequency/severity model extensively used in many applications. It is a parametric technique use internal historical data and sometime enriched by external data to determine the frequency distribution and severity distribution of operational risk for each business line/event type (risk cell) at a specific time horizon. Then a suitable technique (e.g. Monte Carlo simulation or Panjer's recursive algorithms) used to combine the two distribution to obtain aggregate loss for the next period for each risk cell. Then bank can use the Value at Risk or Excepted Shortfall to determine the capital charge need to meet operational risk, $[19,4,28,24,10]$.

The application of this method summarized in the following:

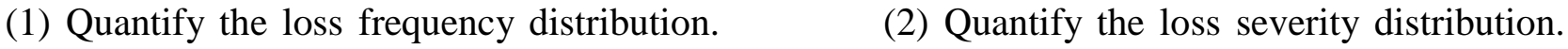

(3) Generate the number $n$ of loss according to the frequency of loss distribution. (4) Generate $X_{i}, i=1, \ldots, n$ losses according to the loss severity distribution. (5) To obtain aggregate operational loss, fin the sum of the generated $X_{i}$. (6) Repeat 3,4 and $5 \mathrm{~m}$ times to obtain total aggregate loss. Then, to find the required capital to meet operational risk, Value at Risk (VaR) or Expected Shortfall (ES) was used, [15, 4].

\subsection{Motivation to improve losses distribution approach}

Although the losses distribution approach is the more common, most theoretical measurement and more risk sensitive approach in operational risk, $[16,4]$, it suffer from some problems as follows: 
- Using Loss Distribution Approach does not enable us to combine different source of data (internal data, external data and scenario analysis) as stated by Basel II, [19].

- Losses Distribution Approach based on historical (external or internal) data to quantify severity and frequency distribution gathered under specific economic condition, which make the estimated capital depend on the assumption that the past condition will extent to the future and these may not true, [7].

- Lack of operational data lead to use external data but using external data doomed by the problem of appropriateness, moreover may lead to false result regarding to the actual severity distribution, [7].

- Estimated capital using Loss Distribution Approach suffer from instability (uncertainty) due to subjectivity in the parametric model assumption, non-robustness to adding small new data or change threshold, and error in parameter estimation, [27].

- There is a need to study both types of event (low frequency/high impact and high frequency/low impact) to estimate operational risk, which is difficult to achieve under LDA.

\section{Preliminaries to fuzzy mathematics}

Due to lack of complete information and increase the complexity of different disciplines, the most mathematical problems are characterized as complex process. Zadeh (1965) introduced fuzzy set theory to handle this, [21]. Application of fuzzy set theory can be found in many disciplines including banking sector. Following are some of the fuzzy definitions that will be used in the next sections.

\subsection{Fuzzy Set}

Fuzzy set define as a class of object has continuum grades of membership. Fuzzy set $\tilde{A}$ can define as follow, let $X$ be a universal set, then the fuzzy set $\tilde{A}$ is given by $\tilde{A}=\left\{\left(x, \mu_{\tilde{A}}(x): x \in X\right)\right\}$. $\mu_{\tilde{A}}(x)$ called the membership function and represent the degree of membership of $x$ in $A, \mu_{A}: X \rightarrow$ $[0,1]$, i.e. $\mu_{\tilde{A}}(x)$ assign to every element $x \in X$ a real number in the interval $[0,1],[18,21]$.

\subsection{Fuzzy Number}

Fuzzy numbers enables to express linguistic variable or fuzzy environment in a mathematical model. A fuzzy number is an extension of a regular number, it does not denote to one single or specified value but rather refer to a values (imprecise or uncertain) of possible connected set, where each possible value has its membership function (weight) between 0 and 1, [21, 22].

Fuzzy number define as a convex and normalized fuzzy set has a membership function defined in $\mathbb{R}$. Convex fuzzy set implies that the line introduced by $\alpha$ cut is continuous and $\alpha$ cut interval comply with the following relation, if $\alpha_{1}<\alpha \Rightarrow a_{1}^{\left(\alpha_{1}\right)} \leq a_{1}^{(\alpha)}, a_{3}^{\left(\alpha_{1}\right)} \geq a_{3}^{(\alpha)}$, where $A_{\alpha}=$ $\left[a_{1}^{(\alpha)}, a_{3}^{(\alpha)}\right]$ and $A_{\alpha_{1}}=\left[a_{1}^{\left(\alpha_{1}\right)}, a_{3}^{\left(\alpha_{1}\right)}\right]$, i.e. $\left(\alpha_{1}<\alpha\right) \Rightarrow\left(A_{\alpha} \subset A_{\alpha_{1}}\right)$. Normalized fuzzy set means that the maximum membership value is 1, i.e. $\exists x_{0} \in R, \mu_{\tilde{A}}\left(x_{0}\right)=1$. Therefore, fuzzy number viewed as a fuzzy set define in a real number interval $\mathbb{R}$ and its boundary is fuzzy, [22, 18, and 21].

\subsection{A triangular fuzzy number}

Among the different shapes of fuzzy numbers, the triangular fuzzy number (TFN) is the most popular one. A triangular fuzzy number $\tilde{A}$ can be represented by a triplet $[a, b, c]$. This representation expressed as membership function given by

$\left\{\begin{array}{ll}\frac{x-a}{b-c} & a \leq x \leq b \\ \frac{c-x}{c-b} & b \leq x \leq c\end{array},[22,18]\right.$.

\subsection{Generate random triangular fuzzy numbers}


DOI: https://dx.doi.org/10.26808/rs.ca.i8v3.03 International Journal of Computer Application (2250-1797)

Issue 8 Volume 3, May-June 2018

To create a triangular fuzzy numbers $\mathrm{A}=\left(x_{1}, x_{2}, x_{3}\right)$ in an interval $[a, b]$, James $\mathrm{J}$. B. and Leonard J. J. [8] follows the following steps:

1- Generate three consecutive random numbers and order them. Thus, we have $v=\left(z_{1}, z_{2}, z_{3}\right)$ where $z_{1}<z_{2}<z_{3}$.

2- Set $x_{j}=(b-a) z_{j}+a, j=1,2,3$ thus we have triangular fuzzy number $\mathrm{A}=\left(x_{1}, x_{2}, x_{3}\right)$.

3- To create $n$ sequence of triangular fuzzy numbers $A_{i}=\left(x_{i 1}, x_{i 2}, x_{i 3}\right), \mathrm{i}=1,2, \ldots, \mathrm{n} ; \quad A_{i}$ in an interval $[a, b]$; repeat step one and step two $n$ times.

Thus we have $v_{i}=\left(z_{i 1}, z_{i 2}, z_{i 3}\right)$ where $z_{i 1}<z_{i 2}<z_{i 3}$ and $x_{i j}=(b-a) z_{i j}+a, i=$ $1,2,3, \ldots, n$ and $j=1,2,3$.

\section{Improving Loss Distribution Approach using fuzzy}

In this section, the triangular fuzzy numbers will be used to improve Losses Distribution Approach to quantify the expected operational loss for next period. We called the proposed method Triangular Fuzzy Number-Loss Distribution Approach (TFN-LDA).

Note: In operational risk, both timing of loss occur and amount of loss (severity) must take in consideration, $[13,24]$.

\subsection{Preliminaries to Triangular Fuzzy Number Loss Distribution Approach (TFN-LDA)}

Measuring operational risk improperly will lead to deceived results and make costly decisions. So improving Loss Distribution Approach will help banks to measure operational risk accurately and build an affective framework to manage it. In Loss Distribution Approach, we quantify the distribution of frequency and the distribution of severity then we use both distributions to generate a large number of frequencies and generate the severity based on these frequency.

Since banks work in fuzzy environment, which increase challenges, complexity, and ambiguity, which force banks to make decisions under uncertain situations, thus using specific distribution to measure operational risk become doubtful. To avoid using specific distribution or assumptions during estimate the expected operational loss, operational risk (frequency and severity) will be expressed as triangular fuzzy number. Triangular fuzzy number was used to present such method stems from that the triplet $[a b c]$ of the triangular fuzzy number can be viewed as the [minimum average maximum] expected loss, which is suitable to financial institutions.

Improving Loss Distribution Approach to estimate the expected operational losses start by using the available operational losses data (severity and frequency). First, to express the frequency and severity in fuzzy triangular number, the lower (optimistic), average (realistic) and upper bound (pessimistic) for frequency $\left[a^{f}\right.$, ave $\left.^{f}, b^{f}\right]$ and the lower (optimistic), average (realistic) and upper bound (pessimistic) for severity $\left[a^{s}\right.$, ave $\left.^{s}, b^{s}\right]$ was determined. Then, generate $m$ sequence triangular frequency fuzzy numbers in the frequency interval $\left[\mathrm{a}^{\mathrm{f}}, \mathrm{b}^{\mathrm{f}}\right]$ using the same idea described in section 5.7. Then, in similar way, the generated triangular frequency fuzzy numbers was used to generate triangular severity fuzzy numbers in the severity interval $\left[\mathrm{a}^{\mathrm{s}}, \mathrm{b}^{\mathrm{s}}\right]$. To express the extreme events we allows to frequency and severity to upsurge and exceed the upper bound of the interval. Then, to estimate the required capital to operational loss, the VaR was used for minimum, average, maximum and extreme column as indicate in the following.

\subsection{Triangular Fuzzy Number Loss Distribution Approach (TFN-LDA) steps}

Supposed that there are $n$ historical operational loss data, the frequency of loss in year $t$ is $f_{t}$ and corresponds total loss is $X_{t}$ as described in table 1 .

\begin{tabular}{|l|l|l|l|l|l|l|}
\hline$F$ & $f_{1}$ & $f_{2}$ & $\ldots$ & $f_{t}$ & $\ldots$ & $f_{n}$ \\
\hline$X$ & $X_{1}$ & $X_{2}$ & $\ldots$ & $X_{t}$ & $\ldots$ & $X_{n}$ \\
\hline
\end{tabular}

Table 1:Operational hstorical data 
The Triangular Fuzzy Number-Loss Distribution Approach (TFN-LDA) steps was given in following:

1) Find the fuzzy interval $\left[a^{f}\right.$, ave $\left.^{\mathrm{f}}, b^{f}\right]$ for frequency

Let $F=\left(f_{1}, f_{2}, \ldots f_{t} \ldots, f_{n}\right)$ be the frequency of operational losses, i.e. $f_{t}$ is the numbers of operational losses in year $t$. The lower, average, and upper frequency $\left[a^{f}, a v e^{f}, b^{f}\right]$, are given by: $a^{f}=\min (F), \operatorname{ave}^{f}=\operatorname{average}(F)$ and $\mathrm{b}^{f}=\max (F)$.

2) Find the fuzzy interval $\left[a^{s}, a^{s} e^{s}, b^{s}\right]$ for severity

Let $X=\left(X_{1}, X_{2}, \ldots X_{t} \ldots, X_{n}\right)$ be the operational losses where the $X_{t}$ represent sum of loss for $f_{t}$. The lower, average, and upper bound of operational losses $\left[a^{s}, a v e^{s}, b^{s}\right]$, are given by $a^{s}=$ $\min (X)$, ave $e^{s} \operatorname{average}(X)$ and $b^{s}=\max (X)$.

3) Generate triangular frequency fuzzy numbers

To generate triangular frequency fuzzy numbers for the operational losses we follow the following steps:

I. Generate consecutive random numbers $v_{i}=\left(z_{i 1}, z_{i 2}, z_{i 3}\right) \in(0,1)$ where $z_{i 1}<z_{i 2}<z_{i 3}$, $i=1,2, \ldots, m$, where $m$ is the number of runs.

II. Generate triangular frequency fuzzy numbers $F_{i}=\left(f_{i 1}, f_{i 2}, f_{i 3}\right)$, for the operational losses (each $F_{i}$ represent the minimum, average and maximum number of loss occur in one year) where:

$$
\begin{gathered}
f_{i 1}=\left(\operatorname{ave}^{f}-a^{f}\right) * z_{i 1}+\boldsymbol{a}^{f}, \\
f_{i 2}=\left(\operatorname{ave}^{\mathrm{f}}-a^{f}\right) * z_{i 2}+\mathrm{ave}^{\mathrm{f}}, \text { and } \\
f_{i 3}=\left(b^{f}-\mathrm{ave}^{\mathrm{f}}\right) * z_{i 3}+\mathrm{ave}^{\mathrm{f}} \\
\left.F_{i}=\left(f_{i 1}, f_{i 2}, f_{i 3}\right)=\left(\operatorname{ave}^{\mathrm{f}}-a^{f}\right) * z_{i 1}+\boldsymbol{a}^{f},\left(\operatorname{ave}^{\mathrm{f}}-a^{f}\right) * z_{i 2}+\operatorname{ave}^{\mathrm{f}},\left(b^{f}-\operatorname{ave}^{\mathrm{f}}\right) * z_{i 3}+\operatorname{ave}^{\mathrm{f}}\right)
\end{gathered}
$$

To reflect the extreme frequency, which mean the frequency of the operational losses become out of our expectation and exceed the upper bound, we use the following equation:

$$
F_{i}=\left(f_{i 1}, f_{i 2}, f_{i 4}\right), f_{i 4}=\left(b^{f}-\mathrm{ave}^{\mathrm{f}}\right) * z_{i 4}+\boldsymbol{b}^{f}, \quad z_{i 4} \in(0,1)
$$

4) Generate triangular severity fuzzy numbers

To generate triangular severity fuzzy numbers according to frequency generated in previous steps, for each $F_{i}=\left(f_{i 1}, f_{i 2}, f_{i 3}\right), i=1,2, \ldots, m$ we generate triangular severity fuzzy numbers $X_{i}=\left(x_{i 1}, x_{i 2}, x_{i 3}\right)$ as follows:

I. Generate consecutive random numbers $v_{h}=\left(z_{h 1}, z_{h 2}, z_{h 3}\right) \in(0,1)$ where $\quad z_{h 1}<z_{h 2}<z_{h 3}$ and $h=1,2, \ldots, f_{i 4}$.

II. Generate triangular severity fuzzy numbers $X_{i}=\left(x_{i 1}, x_{i 2}, x_{i 3}\right)$, where:

$x_{i 1}=\sum_{h=1}^{f_{i 1}}\left(a v e^{s}-a^{s}\right) * z_{h 1}+a^{s}$,

$x_{i 2}=\sum_{h=1}^{f_{i 2}}\left(a v e^{s}-a^{s}\right) * z_{h 2}+$ ave $^{s}$ and

$x_{i 3}=\sum_{h=1}^{f_{i 3}}\left(b^{s}-a v e^{s}\right) * z_{h 3}+$ ave $^{\text {s }} \quad$ i.e.

$X_{i}=\left(x_{i 1}, x_{i 2}, x_{i 3}\right)=\left(\sum_{\mathrm{h}=1}^{\mathrm{f}_{\mathrm{i} 1}}\left(\mathrm{ave}^{\mathrm{s}}-\mathrm{a}^{\mathrm{s}}\right) * \mathrm{z}_{\mathrm{h} 1}+\mathrm{a}^{\mathrm{s}}, \sum_{\mathrm{h}=1}^{\mathrm{f}_{\mathrm{i}}}\left(\mathrm{ave}^{\mathrm{s}}-\mathrm{a}^{\mathrm{s}}\right) * \mathrm{z}_{\mathrm{h} 2}+\mathrm{ave} \mathrm{e}^{\mathrm{s}}, \sum_{\mathrm{h}=1}^{\mathrm{f}_{\mathrm{i} 3}}\left(\mathrm{~b}^{\mathrm{s}}-\right.\right.$ aves) $*$ zh3+aves)

III. To reflect the extreme loss, these means the operational losses become out our expectation, we rename $x_{i 3}$ by $x_{i 4}$ and compute it as follow:

$$
\begin{aligned}
& x_{i 4}=\sum_{h=1}^{f_{i 3}}\left(b^{s}-a v e^{s}\right) * z_{h 4}+\boldsymbol{b}^{s}, \quad z_{h 4} \in(0,1) \quad \text { Thus, } \\
& X_{i}=\left(x_{i 1}, x_{i 2}, x_{i 4}\right)=\left(\sum_{h=1}^{f_{i 1}}\left(a v e^{s}-a^{s}\right) * z_{h 1}+a^{s}, \sum_{h=1}^{f_{i 2}}\left(a v e^{s}-a^{s}\right) * z_{h 2} a v e^{s}, \sum_{h=1}^{f_{i 4}}\left(b^{s}-\right.\right. \\
& \text { aves) } * z h 3+b s \text { (4) }
\end{aligned}
$$

IV. To generate $m$ operational losses repeat step I and II $m$ times. 
DOI: https://dx.doi.org/10.26808/rs.ca.i8v3.03 International Journal of Computer Application (2250-1797)

Issue 8 Volume 3, May-June 2018

5) Use Value at Risk (VaR) to estimate the capital required

To find the capital required to meet operational risk we find the $\mathrm{VaR}$ for $x_{i 1}, x_{i 2}, x_{i 3}$ and $x_{i 4}$ columns. The required capital fall in the interval given by:

$$
\left[\operatorname{VaR}\left(\mathrm{x}_{\mathrm{i} 1}\right)+\operatorname{VaR}\left(\mathrm{x}_{\mathrm{i} 2}\right)+\operatorname{VaR}\left(\mathrm{x}_{\mathrm{i} 3}\right) \quad \operatorname{VaR}\left(\mathrm{x}_{\mathrm{i} 1}\right)+\operatorname{VaR}\left(\mathrm{x}_{\mathrm{i} 2}\right)+\operatorname{VaR}\left(\mathrm{x}_{\mathrm{i} 4}\right)\right]
$$

\subsection{Application}

To apply the proposed method, the data in [9], which obtained from South African retail bank, was used. The data consist of two parts:

1- Operational losses collected during two years $(2004,2005)$. The operational loss (in rand) was summarized in table 2.

\begin{tabular}{|l|l|}
\hline Sum & $31,586,348.00$ \\
\hline mean & 277,073 \\
\hline Minimum & $1,000.00$ \\
\hline Maximum & $9,669,000.00$ \\
\hline Standard Deviation & $1,032,814.09$ \\
\hline \multicolumn{2}{|l|}{ Table 2: Operational losses summary [9] }
\end{tabular}

2- The gross income (in rand) for the last three years (2003, 2004 and 2005) for the same bank, shown in table 3 .

\begin{tabular}{|c|c|c|}
\hline 2003 & 2004 & 2005 \\
\hline $368,097,963$ & $430,860,713$ & $473,321,802$ \\
\hline
\end{tabular}

Table 3: Gross income [9]

\subsection{Present the results obtained in [9]}

Ja'nel E., et al. [9] uses Basic Indicator Approach (BIA) and Loss Distribution Approach to calculate required capital to operational risk. Under BIA, the minimum regulatory capital required to cover the operational losses is 50,891,219 rand for one year. While, under the LDA (they use Poisson distribution for the frequency with mean equal 57 and exponential distribution for severity distribution and generate 5000 yearly losses) they find that the VaR (required capital) at 99.9th is R13 384748 rand for one year.

Ja'nel E., et al. concluded that, under AMA banks might hold less capital comparing to capital calculated under BIA but this might not always happen. For example, if a bank has suffered from large operational loss at the same time the bank gross income has not make much growth, then the capital with the AMA will more than capital with BIA. In addition, Ja'nel E., et al. expected that if the banks have accurate operational loss data the estimated capital using LDA will be more aligned with capital estimated using BIS and with the size of operational risk.

\subsection{Applying the proposed method}

In this paper, the proposed method will be applied with the same data in [9] as follows:

The minimum, average and maximum $\left(\mathrm{a}^{f}, \mathrm{ave}^{f}, \mathrm{~b}^{f}\right)$ for the operational loss frequency was determined. In [9] Ja'nel E., et al. use Poisson distribution for frequency of losses with $\lambda=57$. Since there is no information about the frequency, except that it follow Poisson distribution with mean 57, a 5000 random frequency was generated using Poisson distribution with mean 57 and find the minimum, average, and maximum of the frequency in 5000 run was determined. Thus: $a^{f}=$ 37 , ave $\mathrm{e}^{f}=57, b^{f}=83$. Then the minimum, average and maximum $\left(\mathrm{a}^{\mathrm{s}}\right.$, ave $\left.\mathrm{e}^{\mathrm{s}}, \mathrm{b}^{\mathrm{s}}\right)$ for the severity determined. According to given loss data $\boldsymbol{a}^{\boldsymbol{s}}=1000$, ave $\boldsymbol{e}^{\boldsymbol{s}}=277,073$, and $\boldsymbol{b}^{\boldsymbol{s}}=9669000$

The equations (1) and (2) was used to generate the frequency as described above in section 6.2.

$$
F_{i}=\left(f_{i 1}, f_{i 2}, f_{i 3}\right)=\left(b^{f}-a^{f}\right) * z_{i j}+\boldsymbol{a}^{f}, j=1,2,3
$$


DOI: https://dx.doi.org/10.26808/rs.ca.i8v3.03 International Journal of Computer Application (2250-1797)

Issue 8 Volume 3, May-June 2018

The frequency with extreme occurrences given by:

$$
F_{i}=\left(f_{i 1}, f_{i 2}, f_{i 4}\right)=\left(b^{f}-a^{f}\right) * z_{i j}+\boldsymbol{b}^{f}, j=1,2,4
$$

Then, for each $F_{i}=\left(f_{i 1}, f_{i 2}, f_{i 3}\right), F_{i}=\left(f_{i 1}, f_{i 2}, f_{i 4}\right), i=1,2, \ldots, 10000$ triangular severity fuzzy numbers $X_{i}=\left(x_{i 1}, x_{i 2}, x_{i 3}\right)$ and $X_{i}=\left(x_{i 1}, x_{i 2}, x_{i 4}\right)$ was generated, as described in section 6.2, using equation (3) and (4). For example, for first row in frequency table $F_{1}=\left(f_{11}, f_{12}, f_{13}\right)$ and $F_{1}=$ $\left(f_{11}, f_{12}, f_{14}\right)$ we generate triangular fuzzy severity $X_{1}=\left(x_{11}, x_{12}, x_{13}\right)$ using equation (3) and $X_{1}=\left(x_{11}, x_{12}, x_{14}\right)$ using equation (4).

To find the required capital $\mathrm{VaR}$ was used for each loss columns. The required capital to meet operational loss falls in interval given by:

$$
\left[\operatorname{VaR}\left(\mathrm{x}_{\mathrm{i} 1}\right)+\operatorname{VaR}\left(\mathrm{x}_{\mathrm{i} 2}\right)+\operatorname{VaR}\left(\mathrm{x}_{\mathrm{i} 3}\right) \quad \operatorname{VaR}\left(\mathrm{x}_{\mathrm{i} 1}\right)+\operatorname{VaR}\left(\mathrm{x}_{\mathrm{i} 2}\right)+\operatorname{VaR}\left(\mathrm{x}_{\mathrm{i} 4}\right)\right]
$$

The result of the proposed method was summarized in table 4:

\begin{tabular}{|c|c|}
\hline & VaR at .999 \\
\hline$x_{i 1}$ & 223,314 \\
\hline$x_{i 2}$ & 538,334 \\
\hline$x_{i 3}$ & $9,635,974$ \\
\hline$x_{i 4}$ & $19,027,901$ \\
\hline Required capital & {$[10,397,622 \quad 19,789,549]$} \\
\hline
\end{tabular}

Table 4: the result of the TFN-LDA

The required capital to meet operational risk fall in the interval given by, [10,397,622 19,789,549] Rand.

The result obtained in Ja'nel E., et al. [9] shows a big gap between the actual loss and capital estimated using BIA, which represent more cost for bank. Loss Distribution Approach (LDA) and the proposed method, Triangular Fuzzy Number-Loss Distribution Approach (TFN-LDA), are more accurate than BIS. At the same time, TFN-LDA give the decision maker more flexibility to choice the required capital from specific interval and reflect the possibility of occurring extreme events than LDA which estimate the capital as fixed number which may expose the bank to risk.

\section{Conclusion}

Applying the proposed method increase the accuracy of estimated capital required to operational risk and many produce many benefits:

- Avoid using specific distribution for frequency and severity of operational risk, thus we avoid subjectivity in the parametric model assumption.

- Since VaR fail to estimate or predict losses result from extreme events, (does not measure the risk in the tail). Using the proposed method enables us to avoid this problem and enable bank to study the effect of extreme event easily without needing to use addition techniques Extreme Value Theory for example.

- TFN-LDA gives the decision maker more flexibility to choice the required capital between intervals according to accordance with the changes occurring in the environment surrounding the bank.

\section{References}

I. Antonina Durfee and Alexey Tselykh, Evaluating Operational Risk Exposure Using Fuzzy Number Approach to Scenario Analysis, European Society for Fuzzy Logic and Technology (EUSFLAT-LFA), 2011.

II. Ariane Chapelle, Yves Crama, Georges Hubner, and Jean-Philippe Peters, Practical methods for measuring and managing operational risk in the financial sector: A clinical study, Journal of Banking and Finance, 1049-1061, 2008.

III. Dominik D. Lambrigger, Pavel V. Shevchenko and Mario V. Wüthrich, The quantification of operational risk using internal data, relevant external data and expert opinions, The Journal of Operational Risk, 2(3), 3-27, 2007. 
DOI: https://dx.doi.org/10.26808/rs.ca.i8v3.03 International Journal of Computer Application (2250-1797)

Issue 8 Volume 3, May-June 2018

IV.E. Karam and F. Planchet, Operational Risks in Financial Sectors, Hindawi Publishing Corporation, Advances in Decision Sciences, Volume 2012, article ID 385387, 2012.

V. Fatima Zahra El Arif and Said Hinti, Methods of quantifying operational risk in Banks: Theoretical approaches, American Journal of Engineering Research (AJER, Volume-03, Issue-03, pp-238-244), 2014.

VI. Hylmun Izhar, Measuring Operational Risk Exposures in Islamic Banking: A Proposed Measurement Approach, Islamic Economic Studies, Vol. 20, No.1, 2012.

VII. Imad A. Moosa, A Critique of the Advanced Measurement Approach to Regulatory Capital Against Operational Risk, Journal of Banking Regulation, 2008, 9(3):151-164.

VIII. James J. Buckley and Leonard J. Jowers, Monte Carlo Methods in Fuzzy Optimization, Scientific Publishing Services Pvt. Ltd, 2008.

IX. Ja'nel Esterhuysen, Paul Styger and Gary Van Vuuren, Calculating operational value-at-risk $(\mathrm{OpVaR})$, South African Journal of Economic and Management Sciences" SAJEMS", NS 11, No 1, 2008.

X. Kabir K. Dutta and David F. Babbel, Scenario Analysis in the Measurement of Operational Risk Capital: A Change of Measure Approach, Journal of Risk and Insurance, Volume 81 Issue 2, 2014.

XI. Kashfia N. Rahman, Dennis A. Black, and Gary C. Mcdonald, An Application of Bayesian Inference on the Modeling and Estimation of Operational Risk Using Banking Loss Data, Applied Mathematics, 5, 862-876, 2014.

XII. Marcelo Cruz, Rodney Coleman, and Gerry Salkin, Modeling and measuring operational risk, Journal of Risk, Volume 1/Number 1, 63-72, 1998.

XIII. Marcelo G.Cruz, Modeling, measuring and hedging operational risk, JOHN WIELY \&MSONS, LTD, 2002.

XIV. Milan Rippel and Petr Teply, Operational risk - scenario analysis, Prague economic papers, University of Economics, Prague, 2011.

XV. Milan Rippel and Petr Teply, Operational Risk - Scenario Analysis, Institute of Economic Studies, Faculty of Social Sciences, 2008.

XVI. Milan Rippel and Petr Teply, Overview of Operational Risk Management Methods, World Academy of Science, Engineering and Technology, Volume 6, 2012.

XVII. Ognjen Vukovic, Operational Risk Modeling in Insurance and Banking, Journal of Financial Risk Management, 4, 111-123, 2015.

XVIII. Palash Dutta, Hrishikesh Boruah, and Tazid Ali, Fuzzy Arithmetic with and without using $\alpha$-cut method: A Comparative Study, International Journal of Latest Trends in Computing, Volume 2, Issue 1, 99-107, 2011.

XIX. Pavel V. Shevchenko and Gareth W. Peters, Loss Distribution Approach for Operational Risk Capital Modelling under Basel II: Combining Different Data Sources for Risk Estimation, The Journal of Governance and Regulation, 2(3), pages 33-57, 2013.

XX. Pavel V. Schevchenko, and Mario V. Wuthrich, The Structural Modelling of Operational Risk via Bayesian inference: Combining Loss Data with Expert Opinions", Journal of Operational Risk, vol. 1, no. 3, p. 3-26, 2006.

XXI. Sanhita Banerjee and Tapan Kumar Roy, Arithmetic Operations on Generalized Trapezoidal Fuzzy Number and its Applications, Turkish Journal of Fuzzy Systems, Vol.3, No.1, pp. 16-44, 2012.

XXII. Shang Gao and Zaiyue Zhang, Multiplication Operation on Fuzzy Numbers, JOURNAL OF SOFTWARE, VOL. 4, NO. 4, 331-338, 2009.

XXIII. Shuxia Liu and Haijie Mi, Operational risk quantification for loss frequency using fuzzy simulation, Computer modelling \& new technologies, 18(12C) 577-581, 2014.

XXIV. Stuart A. Klugman, Harry H. Panjer and Gordon E. Willmot, Loss model from data to decisions, John Wiley \& sons, Inc, 2004. 
DOI: https://dx.doi.org/10.26808/rs.ca.i8v3.03 International Journal of Computer Application (2250-1797) Issue 8 Volume 3, May-June 2018

XXV. The Office of the Superintendent of Financial Institutions (OSFI), Capital Adequacy Requirements Guideline, 2012.

XXVI. Valérie Chavez-Demoulin, Paul Embrechts, and Marius Hofert, An extreme value approach for modeling Operational Risk losses depending on covariates, Journal of Risk \& Insurance, vol. 83, issue 3, 735-776, 2016.

XXVII. Xiaoping Zhou, Antonina V. Durfee, and Frank J. Fabozzi, On stability of operational risk estimates by LDA: From causes to approaches, Journal of Banking \& Finance, Volume 68, July 2016, Pages 266-278, 2016.

XXVIII. Yevgen Prokopenko and Denis Bondarenko, Operational Risk Management: Best Practice Overview and Implementation, Risk professional workshop, International Finance Corporation, World Bank Group, 2012. 